\title{
Correction to: Effects of a Contingency for Quiz Accuracy on Exam Scores
}

\author{
Samantha R. Dalfen ${ }^{1} \cdot$ Daniel M. Fienup ${ }^{2} \cdot$ Peter Sturmey $^{1}$ \\ Published online: 2 April 2018 \\ (C) Association for Behavior Analysis International 2018
}

\section{Correction to: Behav Analysis Practice https://doi.org/10.1007/s40617-018-0226-z}

This article was updated with the correct version of Figure 1. Due to an error in production, an older version of Figure 1 was used; Springer regrets the error.

The online version of the original article can be found at https://doi.org/ $10.1007 / \mathrm{s} 40617-018-0226-\mathrm{z}$

$\triangle$ Daniel M. Fienup

fienup@tc.columbia.edu

1 Queens College and The Graduate Center, CUNY, New York, NY, USA

2 Department of Health and Behavior Studies, Teachers College, Columbia University, 525 W. 120th St, Box 223, New York, NY 10027, USA 